\title{
CUIDADO AOS USUÁRIOS DE ÁLCOOL NA ATENÇÃO PRIMÁRIA: MORALISMO, CRIMINALIZAÇÃO E TEORIAS DA ABSTINÊNCIA
}

\author{
CARING FOR ALCOHOL USERS IN PRIMARY HEALTH CARE: MORALISM, \\ CRIMINALIZATION AND ABSTINENCE THEORY
}

CUIDADO DE LOS USUARIOS DE ALCOHOL EN LA ATENCIÓN PRIMARIA: MORALISMO, CRIMINALIZACIÓN Y TEORÍAS DE LA ABSTINENCIA

\author{
Cilene Despontin Malvezzi ${ }^{1}$ \\ Juliana Luporini do Nascimento ${ }^{2}$
}

Resumo Os danos advindos do uso prejudicial de álcool ganharam destaque a partir do século 18, com a ascensão do capitalismo. Medidas de controle governamentais e sanitárias acompanharam a construção sóciohistórica. No Brasil, a Política de Álcool e Drogas do Ministério da Saúde, instituída nos anos 2000, propôs ações de cuidado em rede, incluindo os serviços da atenção primária. Apesar de esforços para qualificar os profissionais, as ações em saúde se mostram pouco acolhedoras, estigmatizantes e ineficazes diante da complexidade do tema. Objetivando conhecer e analisar as crenças e as práticas de saúde no cuidado ao usuário de álcool na atenção primária à saúde, foi realizado este estudo qualitativo com profissionais de saúde de um serviço de atenção primária, utilizando-se da entrevista semiestruturada e da análise de conteúdo. Os referenciais teóricos relacionados à saúde coletiva e às ciências sociais dão sustentação a esta análise. Os resultados apontaram para atitudes moralizantes e preconceituosas, com uma prática que criminaliza o uso de álcool, principalmente nas classes menos favorecidas, pautada por condutas normatizadas, foco na eliminação dos riscos e na abstinência total, em consonância com o modelo biomédico hegemônico, e distante das necessidades dos sujeitos e da complexidade que envolve a questão.

Palavras-chave atenção primária à saúde; alcoolismo; percepção e estigma social.
Abstract The damages resulting from alcohol abuse gained prominence in the eighteenth century, with the rise of capitalism. Sanitary and governmental control measures followed the sociohistorical construction. In Brazil, the Alcohol and Drug Policy of the Ministry of Health, implemented in the first decade of the twentyfirst century, proposed network care actions, including primary health care services. In spite of the efforts to train the professionals, the actions in health are little welcoming, stigmatizing and inefficient due to the complexity of the topic. With the aim of getting to know and analyzing the beliefs and health practices in the care offered to alcohol users in primary health care, we conducted this qualitative research with the health professionals of a primary health care service using semi-structured interviews and content analysis. The theoretical references related to collective health and social sciences support this analysis. The results pointed to moralizing and bigoted attitudes, with a practice that criminalizes alcohol use, mainly among lower-income classes, guided by normalized conducts, with a focus on the removal of risk and on complete abstinence, according to the hegemonic biomedical model, and distant from the needs of the subjects and the complexity that surrounds the issue.

Keywords primary health care; alcoholism; perception and social stigma. 


\section{Introdução}

O uso de bebidas alcoólicas é uma prática milenar e universal em diferentes culturas e contextos e com diferentes propósitos. Ao longo dos séculos XV, XVI e XVII, o consumo de aguardentes popularmente denominadas 'águas da vida' se constituiu como um dos prazeres individuais da população. Todos os países tinham seus destilados típicos e seus rituais de consumo realizados em ambientes públicos como as tavernas e os cabarés (Santos, 1995).

O simbolismo atribuído ao uso de álcool esteve também fortemente ligado aos interesses socioeconômicos dominantes em cada época. Na Idade Média, por exemplo, o uso do vinho foi associado ao sangue de Cristo, o que reitera seu caráter sagrado e econômico, uma vez que as vinhas eram importante fonte de recurso para a Igreja. Na Europa, uma das funções tradicionais das bebidas, sobretudo fermentadas, foi prover fonte segura de água, o que tornava o uso de bebidas alcoólicas uma prática difundida e a abstinência total impraticável (Souza, 2012).

$\mathrm{O}$ fato de serem produzidas a partir de elementos facilmente encontrados na natureza, como água, açúcar, frutas, fermentos e calor, transformou a bebida alcoólica em uma das substâncias psicoativas (SPAs) mais utilizadas (Acioli, 2002). Seu caráter psicoativo foi descoberto no âmbito da medicina clássica do século XVII, como capaz de provocar alterações na percepção, no comportamento e no humor de quem as consumia e responsável por sensações de prazer e alívio da dor. Seu efeito terapêutico foi também incorporado aos cuidados com a higiene do corpo, analgesia e cura das doenças (Souza, 2012).

A partir do século XVIII, emergiram novas configurações nas relações sociais advindas do declínio da era feudal e da consolidação do capitalismo industrial. As exigências da sociedade e da moral burguesa estavam relacionadas à preparação dos indivíduos para os novos processos de trabalho, com ênfase no controle dos corpos e no aumento da produção. No entanto, o consumo cotidiano de bebidas alcoólicas provocava em alguns indivíduos alterações no comportamento e no desempenho no trabalho. Isso passou a preocupar os governantes e exigir da medicina um olhar diferente para a questão, com a valorização dos prejuízos advindos do uso do álcool e a atribuição de caráter patológico a essa prática (Santos, 1995).

A primeira menção à 'doença do alcoolismo' foi feita em 1849 por Magnus Huss, que a designou como um conjunto de sintomas e danos físicos e mentais decorrentes do uso contínuo de bebidas alcoólicas. Entre as consequências sobre o comportamento dos indivíduos estavam a agressividade, a indolência e o descompromisso com o trabalho e a rotina familiar (Santos, 1995; Souza, 2012). 
A preocupação dos governantes em controlar o consumo excessivo de álcool encontrou apoio, para além da medicina, nos princípios religiosos e morais da sociedade. A visão do álcool como pecado e como crime se vinculou ao controle da Igreja e da Polícia, respectivamente. Associações de temperança, com referências religiosas do bem contra o mal, estimulavam verdadeiras cruzadas contra o álcool, visto como um inimigo (Souza, 2012).

Além disso, a internação em manicômios foi a solução proposta para o tratamento dos sujeitos que faziam uso prejudicial de álcool, juntamente com os casos descritos como de vagabundagem e mendicância associados ou não à doença mental. Essa junção de sujeitos em um mesmo espaço para tratamento contribuiu para a associação entre valores morais, doença mental e uso de álcool, o que favoreceu a exclusão social e o estigma que acompanham alguns indivíduos até os dias de hoje.

O movimento pela Reforma Psiquiátrica no Brasil, iniciado na década de 1970, se opôs às formas de tratamento hospitalar que desrespeitavam os direitos humanos dos internos. Conjugado ao movimento pela Reforma Sanitária, na mesma época, trouxe avanços e desafios para a atenção aos portadores de sofrimento mental. Em 2001, a partir da lei federal n. 10.216, a Reforma Psiquiátrica ganhou status de política oficial do Sistema Único de Saúde (SUS). A alternativa ao modelo hospitalocêntrico e excludente foi a constituição gradativa de uma rede de atenção psicossocial, de base comunitária e territorial, composta por serviços de características variáveis, que trabalha em conjunto com a atenção primária à saúde (APS). Iniciou com os Centros de Atenção Psicossocial (CAPSs) e vem se consolidando com os Serviços Residenciais Terapêuticos (SRTs), os Centros de Convivência (Cecos), as enfermarias psiquiátricas em hospitais gerais, as oficinas de geração de renda, os Consultórios de Rua e as Casas Transitórias ou de Passagem. Em 2011, com a instituição da (Rede de Atenção Psicossocial (Raps), a criação e ampliação dos serviços e a articulação entre eles têm sido cada vez mais estimuladas (Brasil, 2011).

No Brasil, o tema do uso de álcool e outras drogas esteve por muito tempo associado à criminalidade e à violência e sob a responsabilidade da justiça e da segurança pública. As ofertas de tratamento eram comumente vinculadas às práticas de exclusão social, em instituições psiquiátricas ou religiosas (comunidades terapêuticas) com foco na abstinência total (Brasil, 2012).

Contrária às práticas de exclusão e à ideia da abstinência total como solução, a Política para Álcool e Drogas do Ministério da Saúde, de 2000, reiterou a responsabilidade pelo cuidado integral aos usuários de álcool e outras drogas apostando na redução de danos, na capacitação dos profissionais, na diminuição do estigma e na construção de uma relação terapêutica singular (Brasil, 2003).

No entanto, a chegada dos usuários com sofrimento mental e dos usuários de álcool e drogas aos serviços da atenção primária tem provocado nos 
profissionais respostas estigmatizantes e pouco acolhedoras, e trazido à tona evidências de conhecimentos insuficientes sobre a complexidade do tema.

Estudos apontam que $22 \%$ da população em geral que chega à atenção primária faz uso de álcool em um nível considerado de alto risco, sem que a suspeição seja feita pelos profissionais, o que reitera o despreparo e a desinformação sobre o tema (Brasil, 2003; Vargas, Bittencourt e Barroso, 2014).

No âmbito das políticas públicas, sugere-se que na APS as ações prioritárias voltadas para os usuários de álcool devem estar focadas na detecção precoce, utilizando-se dos questionários de rastreamento (Audit e Cage), e na intervenção breve, técnica de tratamento baseada em conceitos cognitivocomportamentais voltada para a motivação do usuário e seus familiares para a mudança de hábitos e atitudes. Essas ações ajudam na identificação do padrão de consumo e na sensibilização para a percepção dos danos à sua saúde (Brasil, 2013).

No entanto, apesar dos esforços para qualificar os profissionais da APS, tem sido baixo o impacto na mudança das práticas de saúde. Conforme Souza e Ronzani (2012) e Moretti-Pires e Corradi-Webster (2011), não basta o conhecimento se ele não vier investido de uma mudança de postura e de atitudes dos profissionais. O discurso, principalmente dos médicos, se pauta na dicotomia dependência e não dependência, desconsiderando os diversos padrões de uso existentes. Há uma lógica biomédica hegemônica voltada para a cura das doenças que desconsidera as vulnerabilidades e a relação que o sujeito estabelece com a bebida alcoólica.

Segundo Andrade e Oliveira (2009), os diversos padrões de consumo são definidos de forma multidimensional, considerando a bebida preferida, a frequência, a quantidade e as características individuais do usuário (biológicas, culturais, sociais e econômicas). Reconhecer que existem diferenças entre os sujeitos e entre as formas de beber é primordial para a construção de propostas terapêuticas eficazes.

Estudos evidenciam que o perfil de alguns profissionais inseridos na atenção primária não acompanhou as mudanças propostas nas políticas públicas. Profissionais formados no modelo biomédico têm tido mais dificuldades para romper com paradigmas e incorporar novos olhares e novas formas de fazer, com foco na saúde e não na doença, no coletivo e não no indivíduo, na atuação interdisciplinar e não isolada. Isso se constitui como um desafio aos governantes e às equipes da atenção primária (Moreira e Dias, 2015).

Considerando o exposto, este estudo buscou conhecer e analisar as crenças, as ações e o processo de trabalho que envolve o tema do uso de 
álcool na atenção primária, e contribuir para novas reflexões sobre a complexidade do tema.

\section{Desenho metodológico}

Trata-se de um estudo qualitativo, resultado de dissertação de mestrado em Saúde Coletiva, realizado em um serviço da atenção primária do município de Campinas, no estado de São Paulo.

O serviço escolhido é responsável por aproximadamente 33 mil habitantes (Censo de 2010), composto por cinco equipes de saúde da família e uma equipe de saúde mental. Observa-se que a proporção de usuários por equipe não corresponde ao preconizado pelo Ministério da Saúde, o que pode prejudicar a assistência no que tange à formação de vínculo, à responsabilização, ao desenvolvimento de projetos terapêuticos singulares etc. Nota-se ainda que a presença da equipe de saúde mental enriquece o trabalho multidisciplinar, porém pode favorecer encaminhamentos precoces a esta especialidade.

$\mathrm{Na}$ escolha dos sujeitos procurou-se que estivessem representadas as cinco equipes de saúde da família e as diferentes categorias profissionais. Utilizamos o critério de conveniência para a participação, respeitando a disponibilidade de tempo e horário e o interesse em contribuir com a pesquisa. Quase todos os convidados aceitaram. Apenas um recusou o convite sem apresentar justificativa, e foi substituído por outro profissional.

O critério de saturação delimitou o número de participantes em 12 profissionais, dos quais três homens e nove mulheres, com idades que variaram entre 31 e 59 anos e tempo de trabalho no serviço de 2,5 a 25 anos. Estão assim divididos, conforme as categorias profissionais: dois agentes comunitários de saúde; dois enfermeiros e um técnico de enfermagem; três médicos; um dentista e um técnico de higiene bucal; um assistente social e um educador social. A técnica para a coleta de dados foi a entrevista semiestruturada sobre: crenças sobre o uso de álcool na sociedade e na vida pessoal, crenças sobre o usuário de álcool e as ações de saúde com esses sujeitos. As entrevistas ocorreram entre maio e junho de 2017 e foram realizadas no próprio serviço, durante a jornada de trabalho dos profissionais. Foram audiogravadas e transcritas na íntegra pelas pesquisadoras.

A sistematização dos dados foi feita com base na análise de conteúdo, destacando-se núcleos temáticos e categorias de análise, seguindo as orientações de Bardin (2011).

O estudo foi aprovado pelo Comitê Institucional de Ética em Pesquisa da Universidade Estadual de Campinas mediante o parecer n. 1.313.246, e 
os entrevistados assinaram o Termo de Consentimento Livre e Esclarecido, baseado na resolução CNS n. 466/2012.

\section{O cuidado aos usuários de álcool na atenção primária: análise e discussão dos resultados}

A percepção dos usuários de álcool no cotidiano do serviço foi descrita pelos profissionais a partir de diferentes situações. De forma geral, os relatos cursaram sobre usuários visivelmente alcoolizados perambulando pela unidade; histórias de violência doméstica envolvendo usuários de álcool; exames laboratoriais alterados, assim como problemas com o controle da diabetes e da hipertensão, associados ao uso de álcool; usuários buscando a sala de curativos com ferimentos relacionados a brigas ou quedas após o uso de álcool; ou ainda familiares demandando ajuda para internar seu parente usuário de álcool. No entanto, essas ocorrências não pareceram sensibilizar os profissionais para a dimensão do problema. Apesar de reconhecerem que essas situações evidenciam problemas associados ao uso de álcool, observou-se uma tendência a esperar pela demanda espontânea dos sujeitos por tratamento e a dirigir o foco para a promoção da abstinência total como proposta terapêutica.

Os pacientes chegam, eu acho que assim, pouco perto do que a gente sabe desse problema, dessa doença do alcoolismo. (...) São poucos os que chegam por demanda espontânea, porque querem parar (E6).

Embora estudos reconheçam forte tendência dos usuários a negar os problemas relacionados ao uso de álcool e dificuldade em procurar ajuda espontaneamente, um determinante importante para a conscientização sobre os prejuízos e para a adesão ao tratamento diz respeito ao acesso aos profissionais e aos serviços de saúde. Atitudes acolhedoras e que valorizam a queixa e a demanda do usuário para além da questão do uso de álcool influem significativamente na adesão ao tratamento (Malvezzi et al., 2016; Cardozo, 2014).

Essa tendência a esperar pela demanda espontânea do usuário, acreditando que já se sabe o que é melhor para ele, no caso, a abstinência total, atende a um modelo biomédico tradicional segundo o qual o usuário traz a queixa e o profissional de saúde prescreve a conduta, modelo conhecido popularmente como 'queixa-conduta', mais comum no pronto atendimento. Porém, não responde às necessidades de boa parte dos usuários diante da complexidade do tema, em especial nos serviços da atenção primária.

As particularidades que envolvem o processo saúde-doença, aliadas à complexidade da vida moderna, como as várias formas de violência, as carências sociais, econômicas e afetivas, as escolhas individuais e o desejo de 
correr riscos, por exemplo, mediante o uso abusivo de SPAs, têm exigido respostas dos profissionais que vão além de intervenções medicamentosas ou orientações sobre hábitos considerados saudáveis. No entanto, as equipes parecem se pautar por condutas que enfatizam a prevenção das doenças ao invés da promoção da saúde.

Outro ponto evidenciado nos relatos foi a dificuldade em oferecer cuidado diante dos sentimentos de impotência, raiva e rejeição despertados nessa relação.

Acho que uma pessoa assim atrapalha a rotina do serviço (E1).

Porque é trabalhoso, né? O paciente etilista é... ele dá muito trabalho (E5).

Porque o álcool libera o que o cara tinha de noção de civilidade, né? (E8)

A chegada do sujeito alcoolizado parece desorganizar a rotina e o processo de trabalho, tradicionalmente constituído por procedimentos padronizados e normatizados. Da mesma forma, o comportamento inadequado do sujeito, fora dos padrões de 'civilidade', não se coaduna com a passividade e a submissão às prescrições esperadas da maioria dos usuários. Essa dificuldade dos profissionais diante de situações que fogem do controle sobre os corpos, do controle sobre o biológico, ou de sujeitos que transgridem as regras morais e de conduta restringe a possibilidade de ajuda e reforça a centralidade do modelo biomédico tradicional.

Sinceramente, eu me sinto assim muito despreparada pra lidar com isso. Não só com o alcoolismo. Droga também. O tabagismo nem tanto, porque o tabagismo não causa tantos danos sociais. (E5)

Pressão alta, você dá um remédio e controla. Você passa a monitorar. Agora, o alcoolismo, não. É muito subjetivo. (E5)

O cuidado com foco no biológico, diante de agravos como tabagismo e pressão alta, acreditando-se que basta dar o remédio para controlar o problema, se coaduna com o modelo biomédico tradicional e com uma visão biologista do ser humano, que separa o corpo da mente e desconsidera os determinantes sociais, econômicos, ambientais, psicológicos. De fato, diante de alguns agravos como um infarto agudo do miocárdio ou uma pneumonia ou um pico hipertensivo, exigem-se procedimentos bem delimitados e certa passividade do sujeito. No entanto, todo processo saúde-doença envolve um grau de autonomia do usuário para fazer escolhas e tomar decisões (Merhy e Feuerwerker, 2009). 
Seria a abstinência total a melhor oferta para todos que fazem uso de álcool? Que outras possibilidades terapêuticas são conhecidas pelos profissionais para lidar com os danos sociais e a recusa do usuário a se abster de álcool? As estratégias sugeridas pelas políticas públicas para álcool e drogas na atenção primária estão baseadas na entrevista motivacional e nas intervenções breves. São técnicas que se apoiam nos conhecimentos da psicologia e com as quais se busca: motivar o usuário sem imposições; não confrontá-lo; agir como mediador e facilitador diante da ambivalência entre tratar ou não, e, fundamentalmente, respeitar o seu desejo de fazer uso de álcool (Oliveira et al., 2008).

Contrariando essas orientações, os discursos evidenciaram a postura de questionar o usuário até se confirmar o que se suspeita: o alcoolismo. O diagnóstico parece servir mais para tranquilizar o profissional, assegurando-o de que o seu papel como detentor de um saber em saúde (dar um diagnóstico) foi cumprido, do que problematizar sobre o cuidado que será ofertado.

- Quanto você toma?

- Ah, eu tomo um copinho no fim de semana.

- Quanto é esse copinho no fim de semana?

- Ah, dois copinhos!

- Quanto, quanto é o copinho? - Aí ele vai se abrindo: - Ah, eu tomo isso...

- É só no fim de semana?

- Ah, doutor, de vez em quando eu tomo em casa também...

Aí depois: - Ah, doutor, todo dia eu tomo um copinho.

Então isso é alcoolismo (E4).

Ou então, quando o profissional da atenção primária resolve encaminhar para outros serviços como o pronto atendimento e o Centro de Atenção Psicossocial Álcool e Outras Drogas (CAPSad), há relatos de dificuldades atribuídas ao preconceito que sofrem esses usuários e à sobrecarga dos serviços.

Se eu mandar um cara pra ser internado no PS... "Olha, deixa ele três dias internado pra um tratamento...", o médico vai olhar e vai dar risada na minha cara e vai falar: "Quem é você pra me mandar um paciente de álcool?! Ocupar uma cama aqui pra deixar o cara!..." (E4)

O CAPS é uma coisa complexa pra você encaminhar. Tem toda uma dificuldade e eles também estão sobrecarregados. (E4)

Segundo Monteiro e Vilela (2013), a estigmatização sofrida pelos usuários de álcool e por aqueles que fogem dos padrões morais esperados é uma construção sócio-histórica e cultural que exerce influência sobre as atitudes, crenças e afetos que perpassam a relação entre profissional de saúde e usuário. 
É como se alguns sujeitos ficassem excluídos das ações em saúde em função da forma como decidiram levar suas vidas.

Eu acho que a gente sempre tem uma restrição, né? Usuário de droga, usuário de álcool, né? Bandido que foi baleado e está no hospital, né? A gente é humano também, né? (E8).

Todo mundo aqui na saúde pública já escutou besteira que não era pra escutar porque o paciente estava alcoolizado, estava drogado, não sei o quê, né? (E8)

Ficam implícitos a impotência e o preconceito diante de situações que exigem ações para além do modelo biológico e em que os profissionais tenham que se haver com a opção dos sujeitos por correr riscos. Riscos advindos do uso de SPAs ou de atitudes consideradas imorais e criminosas pela sociedade contemporânea.

Sair do campo das regularidades e controle sobre os fenômenos físicos e as doenças para um campo onde há a imprevisibilidade da vida cotidiana, onde os danos sociais desafiam o que se espera como regras morais e de conduta, exige dos profissionais formados no modelo biomédico abrir mão do saber estruturado com base na doença e restrito ao campo biológico e reconhecer os limites deste para lidar com as novas demandas dos indivíduos e da coletividade.

Diante dos sentimentos e da impotência que os usuários de álcool despertam nos profissionais, recorre-se aos encaminhamentos para a psiquiatria.

Na minha opinião, eu acho que ele é do psiquiatra. O clínico pode até assessorar, trocar uma receita. Vem, faz uma consulta clínica, não sei o quê. Mas eu não vejo assim o clínico com... qualidade assim pra assumir um paciente desse e tocar (E8).

A associação da psiquiatria com o uso de álcool remonta aos séculos passados quando os loucos, usuários de álcool, delinquentes e mendigos eram internados nos mesmos espaços para um tratamento dito moral, e não de saúde. A psiquiatria estava a serviço da correção do que se considerava errado e da adequação da conduta dos indivíduos aos padrões da época. No entanto, não nos parece que as coisas mudaram muito nos dias de hoje. A busca pelos profissionais de saúde mental tem sido feita, em alguns casos, esperando-se a correção dos comportamentos alterados que fogem aos padrões esperados para a vida em sociedade. Haja vista o crescimento dos diagnósticos em psiquiatria e a patologização de comportamentos até há pouco tempo aceitos pela sociedade (agitação em crianças traduzida como hiperatividade ou a tristeza após a morte de um ente querido diagnosticada como depressão). 
Segundo Caponi (2014), a biopolítica, entendida como o exercício de poderes reguladores e disciplinares sobre grupos humanos, busca classificar os assuntos próprios da condição humana em termos de normalidade ou patologia, e tem fundamentado intervenções medicalizantes, psiquiátricas ou não, ao campo do biológico os padecimentos individuais e cotidianos, excluindo as dimensões sociais, afetivas e ambientais.

Perceber, refletir e agir diante dos danos que vão além dos prejuízos biológicos, mais facilmente detectados e controlados, exige dos profissionais de saúde se haver com os valores atribuídos aos sujeitos que usam álcool e aos papéis sociais esperados na sociedade contemporânea. Valores e papéis que refletem o controle do Estado sobre a população, visando à manutenção da ordem e da segurança pública e sanitária (Fiore, 2008).

O usuário de álcool que, apesar de beber, é capaz de desempenhar os papéis de pai, esposo e trabalhador exigidos na sociedade 'civilizada' parece ser mais aceito no serviço e na sociedade e não representar um risco evidente. Da mesma forma, o usuário que chega pedindo ajuda para controlar o hábito de beber é mais tolerado do que aquele que chega alcoolizado ou se recusa a parar de beber totalmente.

Esse discurso pautado pelo controle dos riscos fica evidenciado nas expectativas pelo cumprimento das leis que versam sobre o controle de SPAs.

Eu sei que se diminuísse o álcool do final de semana, se tivesse uma lei seca, o movimento de pronto-socorro, de urgência e emergência diminuiria muito... de $30 \%$ a $35 \%$ de volume, assim (E8).

Não existe nenhuma campanha de prevenção do uso do álcool, pelo contrário. Só há campanha de incentivo ao uso do álcool (E4).

As políticas públicas para o uso de álcool trazem uma série de orientações relacionadas ao álcool e agravos à saúde; álcool e trânsito; venda de álcool para menores de 18 anos; álcool e violência doméstica, homicídio e acidentes (Brasil, 2003). Porém, apesar de se pautarem por medidas regulatórias que restringem o acesso às bebidas alcoólicas, regulam o preço, delimitam uma idade mínima para o consumo e controlam as propagandas, a nosso ver não abrangem a complexidade e o contexto sócio-histórico que envolve essa problemática. Pautam-se por um discurso moralizante que responsabiliza o sujeito pelo controle dos riscos e, baseado em parâmetros para a manutenção da ordem e da segurança pública, desconsidera a singularidade de cada sujeito ou todo o contexto em que o uso de álcool está presente. 
Em consonância com as proposições regulatórias das políticas, há, segundo Castiel (2015), uma visão triunfalista da ciência, pautada por uma cultura securitária e que estimula o autocuidado, que não se coaduna com os vários estímulos da contemporaneidade potencialmente nocivos, como algumas práticas alimentares, o tabagismo, a automedicação e o próprio uso de SPAs, acessíveis e à escolha dos sujeitos. Essa concepção de autocuidado, que visa à domesticação de corpos contra os impulsos considerados nocivos, contribui para culpabilizar o sujeito que 'falha' em adotar um estilo de vida saudável.

Geralmente eu sempre comento assim de bebida, de cigarro, né? Toda vez que eu me lembro de sentir cheiro ou que está escrito... "E aí, parou de beber?" "Ah, estou parando." "Ah, e aí, foi no grupo? De tabaco?" (...) Se tem alteração nos exames a gente orienta a passar na nutrição também, que ela também pega um pouco no pé (E8).

A prática de medicalizar ou vigiar os hábitos relacionados à obesidade, ao uso de álcool e tabaco, à pré-diabetes, impondo medidas de vigilância arbitrárias aos sujeitos, não atende a todos indistintamente e não se coaduna com os princípios de redução de danos, estratégia sugerida pelas políticas públicas, em especial nas adicções (Castiel, 2015). Tais práticas exacerbam o caráter preventivista e biomédico hegemônico, em vez de propor ao usuário uma reflexão sobre a promoção da saúde.

A própria terminologia utilizada pelos profissionais para caracterizar os usuários de álcool sugere uma reflexão. Quando afirmar que o uso de álcool é prejudicial ao sujeito? Quando caracterizá-lo como um 'alcoolista', 'alcoólatra', 'etilista' ou 'bêbado'? Seria de acordo com a quantidade ingerida? O tipo de bebida? A frequência? Embora os profissionais utilizem variadas terminologias, por vezes pejorativas, para designar os usuários, não houve consenso e clareza quanto à definição diagnóstica.

Eles falavam que era... etilista social. Mas aí a gente perguntava: "Mas você bebe quantas vezes?" "Ah, todo fim de semana". Então, eu acho que já é etilista, né? (E5).

Essa prerrogativa que patologiza o uso de álcool independentemente dos danos ao sujeito não tem se mostrado eficaz para lidar com a complexidade que envolve o tema. Os profissionais discorreram com desenvoltura sobre o que consideram grave e prejudicial na forma como a sociedade lida com o uso de SPAs. Porém, o fazem com argumentos que apelam a questões mais morais do que de saúde propriamente. 
É um problema tão grave como o uso de drogas ilícitas, né? Pra mim até mais, porque... pelo fato do álcool ser lícito, né? Infelizmente, é essa a cultura mundial. Não é só aqui no Brasil. Isso transforma o álcool numa patologia que é crônica. Que produz um desastre de problemas clínicos (...) e afeta a parte social da pessoa, destrói. Tanto ou mais que a droga (E4).

Atribuir os problemas com o uso de álcool à sua ilicitude reduz a questão a valores morais - certo e errado, permitido e não permitido -, o que está longe de responder às demandas de saúde.

A classificação de SPAs em lícitas e ilícitas surgiu na virada do século $\mathrm{XX}$, em resposta aos interesses econômicos e de controle do comportamento da sociedade (Fiore, 2008). Essa classificação criminaliza o consumo de certas substâncias, a despeito do comprometimento biopsicossocial que acarreta para o sujeito. Fato é que o consumo de drogas consideradas ilícitas, como a maconha e a cocaína, nem sempre traz prejuízos significativos para o sujeito ou compromete sua funcionalidade em casa, no trabalho e na vida social. Por sua vez, o uso de álcool, que quando em demasia pode trazer consequências danosas para o sujeito e os que convivem com ele, por ser lícito acaba sendo banalizado pela sociedade contemporânea.

Segundo Fiore (2008), essa lógica dicotômica que estabelece o que pode e o que não pode, o que faz bem ou o que faz mal, o que provoca danos ou não ignora características, padrões de consumo e riscos muito diversos na relação que o sujeito desenvolve com as SPAs.

Da mesma forma, a comparação entre SPAs lícitas e ilícitas pode incorrer em minimização dos danos do álcool e do tabaco e em criminalização do usuário de drogas, transformando-os em transgressores de regras que precisam ser punidos e encaminhados para tratamento e correção do que está errado.

Então, o álcool, "Ah, tudo bem. Ele é usuário, ele é alcoólatra, ah, tudo bem!". Entende? Enquanto que... na droga, não "Ah, ele tá usando maconha, ah, então ele precisa ser encaminhado com urgência" (E2).

A cocaína é pior do que o álcool. O álcool também pode acabar com a pessoa. Só que a droga... ela é mais forte e leva as pessoas a fazerem atos que pode até não levar a vida dela pela droga, mas pelos atos: roubo, se prostituir, ir pra rua (E9).

Essa forma de ver o uso de álcool como menos danoso para alguns sujeitos ficou evidenciada quando os profissionais fizeram referência ao seu próprio uso e ao das classes mais favorecidas socioeconomicamente. 
Porque nós temos uma cultura do álcool, né? (...) A gente faz comemorações com álcool, um batizado de uma criança, um aniversário... Faz parte da nossa vida o álcool. (E1)

Eu acho que o álcool é uma substância como outras que a gente acaba usando, né? Na minha vida pessoal eu acho que não tem problema (E6).

A utilização do álcool em contextos comemorativos ou na vida pessoal dos entrevistados sugere uma distinção em relação ao uso feito pelos usuários, considerados aqui como pertencentes a uma classe social menos privilegiada. Além disso, envolve o controle social sobre o uso. É como se fossem eleitos lugares, eventos e classes sociais nos quais o uso de álcool é permitido e esperado e os danos não aparecem ou são minimizados. No entanto, quando o uso está presente nos usuários e no cotidiano dos serviços, há tendência à criminalização e à fatalidade.

No meu mundo social, não. Mas aqui, no mundo do trabalho (...) a população vai a óbito. O encargo que traz pro governo. Porque ele é acidentado, ele dorme no volante, ele perde membro, ele não volta a trabalhar. (E10)

Se você sair assim à noite na periferia, (...) a quantidade de boteco aberto e de gente assim, domingo à noite, de madrugada, quase segunda, sabe? É uma coisa absurda! (E8)

É como se o uso de álcool e a presença de bares nas regiões mais nobres não fossem danosos quando comparados ao 'absurdo' dessas ocorrências nas classes menos favorecidas. Da mesma forma, a aceitação do uso de álcool em alguns contextos fica evidenciada quando o sujeito consegue conciliar o consumo de álcool com o trabalho e uma vida regrada em sociedade e na família. Esse sujeito estaria, então, autorizado a fazer uso de álcool como forma de compensação por seu bom desempenho social.

Trabalhei demais, agora eu mereço uma cervejinha bem gelada. Trabalhei bastante, agora eu mereço (E3).

A própria ocorrência do happy hour delimita um contexto e favorece o controle social sobre o uso. Beber em grupo ou após o trabalho é permitido e glamurizado. Saber beber, sem interferir no bom desempenho dos papéis sociais, se transforma em um valor positivo, porém afeito às classes mais favorecidas.

É muito comum lá nas classes mais pobres o uso de álcool (...) Algumas vezes é a única diversão que eles têm (E8). 
E eu acredito que o ambiente, o território, é muita oferta da bebida. (...) O boteco é na porta da casa, é na própria casa. Tem bebida à vontade na casa (E10).

Mais uma vez, desconsideram-se os inúmeros bares também presentes nos bairros mais nobres. No mesmo sentido, como negar que beber a 'cachaça' tem mais glamur do que beber a 'pinga'? Ou que discursar sobre os diferentes tipos de cerveja ou sobre o envelhecimento do uísque demarcaria diferenças de classe social, faixa etária e gênero, comuns na sociedade contemporânea?

Essa relação entre uso de álcool e pobreza deve ser devidamente problematizada. Adverte Souza (2009, p. 25) para a necessidade de não se reduzir e universalizar algumas associações sem levar em conta "o abandono social e político secular de classes sociais inteiras cotidianamente exercido pela sociedade" privilegiada das classes mais favorecidas que têm melhores oportunidades, capacidade crítica e autonomia para cuidar de si e fazer suas escolhas. Sem falar nas desigualdades educacionais, de raça e de gênero presentes em qualquer associação que envolva o uso de álcool.

No que toca às orientações sugeridas pelas políticas públicas, nos relatos houve pouca referência às estratégias de redução de danos. Isso talvez se deva ao fato de que tais estratégias implicam deslocar o foco da doença e da abstinência para a dimensão singular da experiência com o uso de álcool. Significam deixar o usuário aferir o risco que quer correr, em vez de delimitar o risco para ele. Significa falar em promoção em vez de focar em prevenção. Trazer a redução de danos para a clínica do dia a dia significa saber o que os usuários pensam, dizem e fazem com o desejo de continuar a usar álcool e que regras de cuidado constroem para si (Souza e Carvalho, 2012).

Conforme afirmam Souza e Carvalho (2012), trabalhar com redução de danos implica compreender que nem todas as experiências com SPAs são danosas e que nem todos que têm experiências danosas desejam interromper seu uso. As ações em saúde devem trabalhar na singularidade de cada caso. Um sujeito alcoolizado que procura o serviço de saúde para curar um ferimento com arma branca após uma briga de rua pode não estar pensando em se abster do álcool, apesar da consequência danosa que o uso lhe impôs. Trabalhar na singularidade seria oferecer ajuda para cuidar do ferimento e fortalecer o vínculo para que ele volte em outro momento para falar de sua relação com o álcool.

Pelo exposto, é possível concluir que, no momento em que a narrativa do sujeito passa pelo uso de SPAs, as equipes são atravessadas por valores morais e estigmatizantes que reduzem a capacidade de acolhimento e escuta.

\section{Considerações finais}


A complexidade do processo saúde-doença, em especial nas adicções, representa um desafio para as ações em saúde. Apesar das mudanças na formação acadêmica dos profissionais de saúde, com vistas a ações mais singulares, humanizadas e adequadas às necessidades dos sujeitos, algumas práticas continuam centradas no modelo biomédico e em procedimentos estruturados voltados para a dimensão biológica, para o controle dos riscos e para a cura das doenças.

Da mesma forma, a interação entre profissional e usuário permanece pautada por discursos normativos e proibitivos que impedem a construção da autonomia dos usuários para decidir sobre os riscos e sobre como querem cuidar de sua saúde ou doença. A perda do controle sobre a vida do outro provoca nos profissionais frustração e raiva, que por sua vez levam à exclusão do sujeito e ao desinvestimento nas ações.

Aliados a isso, a criminalização e o processo de estigmatização do usuário de álcool levam a práticas moralizantes, pouco problematizadas, com juízos de valor entre certo e errado, entre permitido e proibido de acordo com a classe social, o que dificulta a autonomia do usuário no cuidado com sua saúde. A dificuldade de incorporar o subjetivo e a singularidade de cada caso e a necessidade de discernir entre o que pertence à esfera da saúde e o que concerne à saúde mental acabam por levar a que se delegue a esta a prerrogativa de cuidar e corrigir o que se considera estar errado nos sujeitos.

Os apontamentos deste estudo indicam ser necessária uma reflexão sobre as crenças e as condutas dos profissionais, por vezes preconceituosas, moralizantes ou amparadas em conhecimentos insuficientes ou equivocados, que dificultam ações em saúde mais condizentes com as demandas da sociedade contemporânea e com a gestão dos riscos.

\section{Colaboradores}

Cilene Despontin Malvezzi e Juliana Luporini do Nascimento trabalharam em todas as etapas da pesquisa e da produção do artigo. 
Resumen Los daños derivados del uso perjudicial del alcohol cobraron importancia a partir del siglo 18, con el ascenso del capitalismo. Medidas de control gubernamentales y sanitarias formaron parte de la construcción sociohistórica. En Brasil, la Política de Alcohol y Drogas del Ministerio de Salud, instaurada en los años 2000, propuso acciones de cuidado en red incluyendo los servicios de atención primaria. A pesar de los esfuerzos para cualificar a los profesionales, las acciones en salud se muestran poco acogedoras, estigmatizadoras e ineficaces frente a la complejidad del tema. Con el objetivo de conocer y analizar las creencias y las prácticas de salud en el cuidado al usuario de alcohol en la atención primaria de la salud, se realizó este estudio cualitativo con profesionales de la salud de un servicio de atención primaria, utilizando como herramientas la entrevista semiestructurada y el análisis de contenido. Los marcos teóricos relacionados a la salud colectiva y a las ciencias sociales proporcionan sustento a este análisis. Los resultados indican actitudes moralizadoras y prejuiciosas, con una práctica que criminaliza el uso de alcohol, principalmente en las clases menos favorecidas, pautada por conductas normalizadas, enfoque en la eliminación de los riesgos y en la abstinencia total, en línea con el modelo biomédico hegemónico y alejadas de las necesidades de los sujetos y la complejidad que implica este tema.

Palabras clave atención primaria a la salud; alcoholismo; percepción y estigma social.

\section{Notas}

${ }^{1}$ Prefeitura Municipal de Campinas, Secretaria de Saúde, Campinas, São Paulo, Brasil. $<$ cilenemalvezzi@yahoo.com.br>

Correspondência: Avenida Synésio Siqueira, 111, CEP 13091-705, Campinas, São Paulo, Brasil.

${ }^{2}$ Universidade Estadual de Campinas, Departamento de Saúde Coletiva, Campinas, São Paulo, Brasil. <jluporini10@hotmail.com> 


\section{Referências}

ACIOLI, Moab D. O processo de alcoolização entre os Pankararu: um estudo em etnoepidemiologia. 2002. 341f. Tese (Doutorado em Saúde Coletiva) - Universidade Estadual de Campinas, Campinas, São Paulo, 2002.

ANDRADE, Arthur G.; OLIVEIRA, Lúcio G. Principais consequências em longo prazo relacionadas ao consumo medrado de álcool. In: ANDRADE, Arthur G. (org.). Álcool e suas consequências: uma abordagem multiconceitual. Barueri: Minha Editora, 2009. p. 37-66.

BARDIN, Laurence. Análise de conteúdo. Tradução de Luis Antero Reto e Augusto Pinheiro. São Paulo: Edições 70, 2011.

BRASIL. A politica do Ministério da Saúde para a atenção integral a usuários de álcool e outras drogas. 2. ed. rev. e ampl. Brasília, DF: Ministério da Saúde, 2003.

BRASIL. Ministério da Saúde. Gabinete do Ministro. Portaria n. 3.088, de 23 de dezembro de 2011. Institui a Rede de Atenção Psicossocial para pessoas com sofrimento ou transtorno mental e com necessidades decorrentes do uso de crack, álcool e outras drogas, no âmbito do Sistema Único de Saúde (SUS). Diário Oficial [da] República Federativa do Brasil, Poder Executivo, Brasília, DF, n. 251, 30 dez. 2011, Seção 1, p. 59.

BRASIL. Ministério da Saúde. Secretaria de Atenção à Saúde. Departamento de Atenção Básica. Política Nacional de Atenção Básica/ Ministério da Saúde. Secretaria de Atenção à Saúde. Departamento de Atenção Básica. Brasília, DF: Ministério da Saúde, 2012.

BRASIL. Ministério da Saúde. Secretaria de Atenção à Saúde. Departamento de Atenção Básica. Saúde mental. Ministério da Saúde, Secretaria de Atenção à Saúde, Departamento de Atenção Básica, Departamento de Ações Programáticas Estratégicas. Brasília: Ministério da Saúde, 2013. 176 p. (Cadernos de Atenção Básica, n. 34).
CAPONI, Sandra. Viver e deixar morrer: biopolítica, risco e gestão das desigualdades. Revista Redbioética/Unesco, Montevideo, año 5, v. 2, n.10, p. 27-37, jul.-dic. 2014.

CARDOZO, Raquel V. Medicalização e o cuidado em saúde na Estratégia de Saúde da Família. 2014. 268f. Dissertação (Mestrado em Saúde Coletiva) - Universidade Estadual de Campinas, Campinas, São Paulo, 2014.

CASTIEL, Luis David. A promoção de saúde baseada em tecnologias de melhoramento: apontamentos sobre a busca da vitalidade a mais eterna possível. In: NOGUEIRA, Roberto P. et al. Observatório internacional de capacidades humanas, desenvolvimento e politicas públicas: estudos e análises 2. Brasília, UnB/ ObservaRH/Nesp - Fiocruz/Nethis, 2015. p 229-259.

FIORE, Maurício. Uso de drogas: controvérsias médicas e debate público. Campinas: Mercado de Letras, 2008.

MALVEZZI, Cilene D. et al. Adesão ao tratamento pela equipe de um serviço de saúde mental: estudo exploratório. Online Brazilian Journal of Nursing, Niterói, v. 15, n. 2, June 2016. Disponível em: http://www.objnursing. uff.br/index.php/nursing/article/view/5201 Acesso em 24/05/18.

MERHY, Emerson E. e FEUERWERKER, Laura C. M. Novo olhar sobre as tecnologias de saúde: uma necessidade contemporânea. In: MANDARINO, Ana C. S. e GOMBERG, Estélio (orgs.). Leituras de novas tecnologias e saúde. São Cristóvão: Editora UFS, 2009. p. 29-74.

MONTEIRO, Simone e VILELA, Wilza (orgs.). Estigma e Saúde. Rio de Janeiro: Editora Fiocruz, 2013.

MOREIRA, Carlos O. F. e DIAS, Maria S. A. Diretrizes curriculares na saúde e as mudanças nos modelos de saúde e de educação. $A B C S$ Health Sciences, Santo André, v. 40, n. 3, p. 300-305, 2015. 
MORETTI-PIRES, Rodrigo O. e CORRADIWEBSTER, Clarissa M. Implementação de intervenções breves para uso problemático de álcool na atenção primária, em um contexto amazônico. Revista Latino-Americana de Enfermagem, Ribeirão Preto, v. 19, n. esp., p. 813-820, jun. 2011.

OLIVEIRA, Margareth S. et al. A entrevista motivacional com alcoolistas: um estudo longitudinal. Psicologia: Reflexão e Crítica, Porto Alegre, v. 21, n. 2, p. 261-266, 2008.

SANTOS, Fernando S. D. A invenção de uma doença. 171f. Dissertação (Mestrado em História) - Universidade Estadual de Campinas, Campinas, São Paulo, 1995.

SOUZA, Isabel C. W. e RONZANI, Telmo M. Álcool e drogas na atenção primária: avaliando estratégias de capacitação. Psicologia em Estudo, Maringá, v. 17, n. 2, p. 237-246, jun. 2012.

SOUZA, Jessé. Ralé brasileira: quem é e como vive. Colaboração: André Grillo et al. Belo Horizonte: Editora UFMG, 2009.
SOUZA, Luiz G. S. Profissionais de saúde da família e representações sociais do alcoolismo. 2012. 637f. Tese (Doutorado em Psicologia) - Universidade Federal do Espírito Santo, Vitória, Espírito Santo, 2012.

SOUZA, Tadeu P. e CARVALHO, Sérgio R. Reduzindo danos e ampliando a clínica: desafios para a garantia do acesso universal e confrontos com a internação compulsória. Polis e Psique, Porto Alegre, v. 2, n. tem., p. 37-58, 2012.

VARGAS, Divane; BITTENCOURT, Marina N.; BARROSO, Lúcia P. Padrões de consumo de álcool de usuários de serviços de atenção primária à saúde de um município brasileiro. Ciência \& Saúde Coletiva, Rio de Janeiro, v. 19, n. 1, p. 17-25, jan. 2014.

Recebido em 18/09/2017.

Aprovado em 14/02/2018 